\title{
SUSCEPTIBILITY OF STAPHYLOCOCCUS AUREUS ISOLATES TO VANCOMYCIN AT A UNIVERSITY HOSPITAL IN SOUTHERN BRAZIL
}

\author{
Larissa Lutz; Afonso Luís Barth* \\ Unidade de Microbiologia e Biologia Molecular, Serviço de Patologia Clinica, Hospital de Clínicas de Porto Alegre, Porto \\ Alegre, RS, Brasil
}

Submitted: January 03, 2006; Returned to authors for corrections: February 23, 2006; Approved: May 23, 2006

\section{SHORT COMMUNICATION}

\begin{abstract}
The in vitro susceptibilty of Staphylococcus aureus to vancomycin was evaluated from impatients at a Brazilian University Hospital by the Etest and a screening method. No vancomycin intermediate (VISA) or vancomycin resistant (VRSA) S. aureus isolate was identified. Three patients presented as heteroresistant VISA (h-VISA) isolates but none of them received vancomycin previously.
\end{abstract}

Key words: S. aureus, vancomycin, VISA, h-VISA

Staphylococcus aureus is one of the most common causes of both nosocomial and community-acquired infections, with high rates of mortality (13). S. aureus has demonstrated an impressive ability to become resistant to nearly all antistaphylococcal agents used in clinical practice (10). In 1996, $S$. aureus with reduced susceptibility to vancomycin (vancomycin intermediate $S$. aureus [VISA]) was reported in Japan (4) and subsequent reports of such isolates were described worldwide (5). The expression "heteroresistant VISA" (h-VISA) was used to denote S. aureus with a subpopulation able to grow on a screening agar plate containing $4 \mathrm{mg} / \mathrm{L}$ of vancomycin. h-VISA is considered definite if the subpopulation vancomycin MIC is at least $8 \mathrm{mg} / \mathrm{L}$ (3). It has been described that h-VISA are widely disseminated and account for 5 to $26 \%$ of the MRSA clinical isolates obtained from Japanese University Hospitals (3). Our aim was to evaluate the in vitro susceptibility of $S$. aureus to vancomycin and the relation with previous use of vancomycin for impatients at a tertiary University Hospital in Southern Brazil (Hospital de Clínicas de Porto Alegre).

A total of 369 S. aureus clinical isolates was obtained from blood cultures of inpatients at Hospital de Clínicas de Porto Alegre between May 1999 and April 2001. Blood cultures were performed using the Bactec $^{\circledR}$ system (Becton Dikinson, Sparks, USA) and S. aureus was identified by standard methods (8). The isolates were tested for susceptibility to penicillin $(10 \mu \mathrm{g})$, oxacillin $(1 \mu \mathrm{g})$, amoxicillin/clavulanic acid $(20 / 10 \mu \mathrm{g})$, erythromycin $(15 \mu \mathrm{g})$, gentamicin $(10 \mu \mathrm{g})$, clindamycin $(2 \mu \mathrm{g})$, rifampin $(5 \mu \mathrm{g})$, trimethoprim-sulfamethoxazole $(1.25 / 23.75 \mu \mathrm{g})$ and vancomycin $(30 \mu \mathrm{g})$ (Oxoid, Basingstoke, UK) by the disc diffusion method according to "National Committee for Clinical Laboratory Standards" (NCCLS) (9). The Etest (AB Biodisk, Solna, Sweden) was performed to determine the vancomycin MIC according to the manufactures. Screening for h-VISA isolates was performed randomly and in duplicate. Inoculum of $10^{6} \mathrm{CFU} / \mathrm{mL}$ of properly diluted overnight cultures of the isolates were spread onto a brain-heart infusion (BHI) agar plate (Oxoid) containing $4 \mathrm{mg} / \mathrm{L}$ of vancomycin (Sigma, St. Louis, Mo). The plates were incubated at $35^{\circ} \mathrm{C}$ and the cell growth was inspected at 24 and $48 \mathrm{~h}$. If confluent growth appeared within $24 \mathrm{~h}$ or no growth appeared within $48 \mathrm{~h}$, the isolate would be considered a potential VISA isolate or susceptible to vancomycin (VSSA), respectively. The isolate would be designated as a possible h-VISA if a countable

*Corresponding Author. Mailing address: Hospital de Clínicas de Porto Alegre, Unidade de Microbiologia e Biologia Molecular, Serviço de Patologia Clínica. Rua Ramiro Barcelos, 2350. 90035-003, Porto Alegre, RS, Brasil. Tel.: (+5551) 3316-8607, Fax: (+5551) 3316-8310. E-mail: albarth@hcpa.ufrgs.br 
number of colonies was appeared within $48 \mathrm{~h}$. h-VISA status would be considered definite if the isolate produced subclones with a vancomycin MIC $\geq 8 \mathrm{mg} / \mathrm{L}$ and with MIC stability persisting beyond 9 days in a drug-free medium (3). Macrorestriction analysis with SmaI (Gibco BRL, USA) of chromosomal DNA followed by PFGE was performed and interpreted as previously described $(7,11)$. The previous use of vancomycin was established after retrospective evaluation of patients data records. S. aureus ATCC 25923 and S. aureus ATCC 29213 were used for quality control of disc diffusion and standard Etest methods, respectively. S. aureus ATCC 29213 and a clinical isolate of Enterococcus faecalis resistant to vancomycin were used as quality control of the vancomycin screening plates.

Our study showed that neither vancomycin intermediate (VISA) nor vancomycin resistant (VRSA) isolates were identified among $369 \mathrm{~S}$. aureus from Hospital de Clínicas de Porto Alegre. In fact, all isolates also proved to be susceptible to vancomycin by the disc diffusion method and by the Etest (MIC ranged from 0.25 to $3.0 \mathrm{mg} / \mathrm{L})$. A total of $218(60.7 \%)$ isolates was susceptible to oxacillin (MSSA), while 141 (39.3\%) isolates proved to be resistant (MRSA). A total of 10 isolates were not evaluated for the susceptibility to oxacillin because they became non-viable after subculture. The majority of MRSA (41.9\%) was susceptible only to rifampin and vancomycin, while $41.1 \%$ of MRSA was susceptible only to vancomcycin.
No isolate displayed confluent growth within $24 \mathrm{~h}$ of incubation on BHI agar with $4 \mathrm{mg} / \mathrm{L}$ of vancomycin, although one to 100 colonies were seen on the screening agar plate for 18 isolates (12 MRSA and 6 MSSA) after $48 \mathrm{~h}$ (Table 1). They were considered as possible h-VISA and their vancomycin MIC were established. Only three isolates (all MRSA) displayed a MIC $\geq 8 \mathrm{mg} / \mathrm{L}$ and were termed selected strains but none had the MIC confirmed after 9 days in drug-free medium. Comparison of the three selected strains and their parental strains by PFGE patterns demonstrated that each pair displayed undistinguishable banding patterns. Therefore, if there was heteroresistance to vancomycin among these isolates it was not a stable trait, as also demonstrated by others studies $(1,6)$. It has been shown by other authors that h-VISA may return to susceptible levels (vancomycin $\mathrm{MIC} \leq 2 \mathrm{mg} / \mathrm{L}$ ) after serial passages through drug-free medium (5). However, these revertants tended to become h-VISA at higher frequencies when exposed to vancomycin. This finding indicates that, although the h-VISA isolates may not disseminate as a stable resistance phenotype, they can readily revert to h-VISA when exposed to vancomycin $(2,5)$.

We were not able to establish a relation between previous use of vancomycin and h-VISA as the three isolates selected by vancomycin screening plate were obtained from patients whom were not receiving vancomycin previously. Therefore,

Table 1. Features of heterogeneously vancomycin-resistant S. aureus isolates selected on BHI screening plates

\begin{tabular}{ccccccc}
\hline Isolates & $\begin{array}{c}\mathrm{h} \text {-VISA } \\
\text { screening }\end{array}$ & $\begin{array}{c}\text { Vancomycin MIC } \\
\text { (Etest) after } \\
\text { screening }\end{array}$ & $\begin{array}{c}\text { Vancomycin MIC } \\
\text { (Etest) of parent } \\
\text { strains }\end{array}$ & $\begin{array}{c}\text { Vancomycin MIC } \\
\text { (Etest-M) of parent } \\
\text { strains }\end{array}$ & $\begin{array}{c}\text { Susceptibility } \\
\text { for methicillin }\end{array}$ & $\begin{array}{c}\text { Previous use } \\
\text { of vancomycin }\end{array}$ \\
\hline 242 & $1-1^{\text {a }}$ & 12.0 & 1.5 & 6.0 & MRSA & NO \\
195 & $20-50$ & 8.0 & 2.0 & 16.0 & MRSA & NO \\
202 & $1-1$ & 8.0 & 1.5 & 8.0 & MRSA & NO \\
245 & $20-20$ & 6.0 & 2.0 & 16.0 & MRSA & YES \\
71 & $1-2$ & 6.0 & 2.0 & 4.0 & MRSA & NO \\
190 & $5-15$ & 6.0 & 0.5 & 6.0 & MSSA & NO \\
209 & $100-100$ & 4.0 & 3.0 & 8.0 & MRSA & YES \\
103 & $6-12$ & 4.0 & 1.0 & 6.0 & MRSA & YES \\
76 & $100-100$ & 4.0 & 2.0 & 12.0 & MSSA & NO \\
203 & $1-4$ & 4.0 & 1.5 & 6.0 & MRSA & NO \\
193 & $5-6$ & 3.0 & 2.0 & 8.0 & MSSA & NO \\
121 & $1-1$ & 3.0 & 2.0 & 4.0 & MRSA & NO \\
165 & $1-1$ & 3.0 & 1.5 & 3.0 & MSSA & NO \\
171 & $8-10$ & 3.0 & 1.5 & 4.0 & MRSA & NO \\
246 & $20-20$ & 3.0 & 1.5 & 3.0 & MSSA & NO \\
178 & $1-1$ & 2.0 & 1.5 & 8.0 & MSSA & NO \\
179 & $1-2$ & 1.5 & 1.5 & 3.0 & MRSA & YES \\
170 & $1-1$ & 1.5 & & & YES \\
\hline
\end{tabular}

${ }^{a}$ Number of colonies on the vancomycin screening agar plate (duplicate). 
whether the isolation of h-VISA from patients could be related to the apparent failure of vancomycin therapy remains controversial. There are recent observations that vancomycin resistance could emerge without previous use of glicopeptide antibiotics (14). The presence of h-VISA may be an important indicator of the insidious decline of the clinical effectiveness of vancomycin in the hospitals (5) but routine screening of $S$. aureus isolates for vancomycin-heteroresistant subpopulations may not be recommended if clinical data are not available to assess the significance of heteroresistance. Such screening may be undertaken as part of research protocols, but results generated using h-VISA screening methods should not be reported in a patient data record (12).

\section{ACKNOWLEDGMENTS}

We thank all staff of "Unidade de Microbiologia - Serviço de Patologia Clínica - Hospital de Clínicas de Porto Alegre", Brazil, for their help to collect the $S$. aureus isolates. This study was partially supported by "Fundo de Incentivo à Pesquisa e Eventos - Hospital de Clínicas de Porto Alegre", Brazil.

\section{RESUMO}

\section{Suscetibilidade de amostras de Staphylococcus aureus à vancomicina isoladas em um hospital universitário no sul do Brasil}

A suscetibilidade in vitro de Staphylococcus aureus à vancomicina foi avaliada em pacientes internados em um Hospital Universitário Brasileiro pelo Etest e por um método de triagem. Nenhuma amostra de S. aureus resistente (VRSA) ou com resistência intermediária (VISA) à vancomicina foi isolada. Três pacientes tiveram amostras heteroresistentes VISA (hVISA), mas nenhum destes recebeu vancomicina previamente.

Palavras-chave: S. aureus, vancomicina, VISA, h-VISA

\section{REFERENCES}

1. Boyle-Vavra, S.; Berke, S.K.; Lee, J.C.; Daum, R.S. Reversion of the glycopeptide resistance phenotype in Staphylococcus aureus clinical isolates. Antimicrob. Agents Chemother, 44(2), 272-277, 2000.
2. Cui, L.; Ma, X.; Sato, K.; Okuma, K.; Tenover, F.C.; Mamizuka, E.M.; Gemmell, C.G.; Kim, M-N.; Ploy, M.C.; Solh, N.E.; Ferraz, V.; Hiramatsu, K. Cell wall thickening is a common feature of vancomycin resistance in Staphylococcus aureus. J. Clin. Microbiol., 41(1), 5$14,2003$.

3. Hiramatsu, K.; Aritaka, N.; Hanaki, H.; Kawasaki, S.; Hosoda, Y.; Hori, S.; Fukuchi, Y.; Kobayashi, I. Dissemination in Japanese hospitals of strains of Staphylococcus aureus heterogeneously resistant to vancomycin. Lancet, 350, 1670-1673, 1997.

4. Hiramatsu, K.; Hanaki, H.; Ino, T.; Yabuta, K.; Oguri, T.; Tenover, F.C. Methicillin-resistant Staphylococcus aureus clinical strain with reduced vancomycin susceptibility. J. Antimicrob. Chemother., 40, 135-146, 1997.

5. Hiramatsu, K. Vancomycin-resistant Staphylococcus aureus: a new model of antibiotic resistance. Lancet Infect. Dis., 1, 147-155, 2001.

6. Hubert, S.K.; Mohammed, J.M.; Fridkin, S.K.; Gaynes, R.P.; McGowan, J.E. Jr.; Tenover, F.C. Glycopeptide-intermediate Staphylococcus aureus: evaluation of a novel screening method and results of a survey of selected U.S. hospitals. J. Clin. Microbiol., 37(11), 3590-3593, 1999.

7. Kaufmann, M.E.; Pitt, T.L. Pulsed-field gel electrophoresis of bacterial DNA. In: Chart, H. (ed). Methods in Practical Laboratory Bacteriology. CRC Press, London, 1994, p.83-92.

8. Kloos, W.E.; Bannerman, T.L. Staphylococcus and Micrococcus. In: Murray, P.R.; Baron, E.J.; Pfaller, M.A.; Tenover, F.C.; Yolken, R.H. (ed). Manual of Clinical Microbiology. American Society for Microbiology, Washington, DC, 1999, p.264-282.

9. NCCLS. Performance standards for antimicrobial susceptibility testing. Twelfth Informational Supplement M100-S12. National Committee for Clinical Laboratory Standards, Villanova, PA. 2002.

10. Paulsen, I.T.; Firth, N.; Skurray, R.A. Resistance to antimicrobial agents other than beta-lactams. In: Crossley, K.B.; Archer, G.L. (ed). The staphylococci in human disease. Churchill Livingstone, New York, N. Y., 1997, p.175-212.

11. Tenover, F.C.; Arbeit, R.D.; Goering, R.V.; Mickelsen, P.A.; Murray, B.E.; Persing, D.H.; Swaminathan, B. Interpreting chromosomal DNA restriction patterns produced by pulsed-field gel electrophoresis: criteria for bacterial strain typing. J. Clin. Microbiol., 33, 22332239, 1995.

12. Tenover, F.C.; Biddle, J.W.; Lancaster, M.V. Increasing resistance to vancomycin and other glycopeptides in Staphylococcus aureus. Emerg. Infect. Dis., 7(2), 327-332, 2001.

13. Wenzel, R.P.; Nettleman, M.D.; Jones, R.N.; Pfaller, M.A. Methicillin-resistant Staphylococcus aureus: implications for the 1990s and effective control measures. Am. J. Med., 91(3B), 22152275, 1991.

14. Whitener, C.J.; Park, S.Y.; Browne, F.A.; Browne, F.A.; Parent, L.J.; Julian, K.; Bozdogan, B.; Appelbaum, P.C.; Chaitram, J.; Weigel, L.M.; Jernigan, J.; McDougal, L.K.; Tenover, F.C.; Fridkin, F.K. Vancomycin-resistant Staphylococcus aureus in the absence of vancomycin exposure. Clin. Inf. Dis., 38, 1049-55, 2004. 